\title{
EDITORIAL
}

\section{Critical results communication: quality and patient safety}

\author{
Leonardo de Souza Vasconcellos
}

Communication of critical results is an old laboratory practice, with the first reports published in the literature at the beginning of the 1970s. However, it was just from the 1990s that this routine became definitely recommended ${ }^{(2)}$. Nowadays, the notification of critical results is part of laboratory indicators that aim at quality and patients' safety ${ }^{(1,5)}$.

The Accreditation Program for Clinical Laboratories (PALC 2013) of Sociedade Brasileira de Patologia Clínica/Medicina Laboratorial (SBPC/ML) defines critical values as "results of laboratory exams that lie within a range of quantitative results or that, per se, may be related to potentially dangerous clinical situations and that must be immediately reported to the attending physician"(3).

In the PALC 2013 guidelines, this subject is developed in several chapters: Chapter 3 - Document management and control; Chapter 4 Management of technical records and quality; Chapter 10 - Management of remote laboratory tests; Chapter 16 - Management of the laboratory information system (SIL); and, principally, Chapter 17 - Management of risk and patients' safety ${ }^{(3)}$.

Item 17.8 of PALC 2013 states that "concerning the post-analytical phase, the clinical laboratory must implement a formal policy and produce documents to guide the reporting of potentially critical results, preferably to the physician or clinical staff. Criteria for potentially critical results must be established preferably in cooperation with other heads of the institution where the laboratory is housed and based on the literature"(3).

As to the procedure of critical results communication, item 17.9 (revised item) of PALC 2013 guidelines states: "there must be: a) definition of the results considered potentially critical and to whom they must be reported; b) definition of mechanisms to identify the results considered potentially critical, during analytical or post-analytical phases; c) definition of who is authorized and is responsible for the communication, and who is authorized to receive the reported results; d) definition of the time considered acceptable between result availability and effective notification (or notification attempt); e) definition of indicator(s) of critical results notification effectiveness" (3).

As to the recording of critical results communication, the PALC 2013 guidelines added item 17.10, which affirms "critical results communication must be adequately recorded, even when the call was not completed. These records must include: a) potentially critical result; b) date and time; c) person responsible for the notification; d) notified person; or e) impossibility of communication and reason" (3).

Therefore, it is important that each clinical laboratory compiles its own list of critical values, preferably with the support of a medical team and of the literature. This list generally comprises hematological, biochemical, serological, toxicological and microbiological tests. However, its content must be in accordance with the laboratory characteristics and degree of complexity, as well as with the profile of patients or clients served by it.

Even if the test is performed outside the laboratory setting, in remote laboratory testing or point-of-care testing (POCT), or if it is outsourced to a support laboratory, the results considered critical must be properly recorded and notified ${ }^{(1-3,5)}$.

Within this context, the present issue of the Brazilian Journal of Pathology and Laboratory Medicine (JBPML) brings an article entitled "Implementation, validation and review of a critical values list in a cardiac emergency room"(4). In this work authors describe the experience of implementing, validating and reviewing a critical values list at a laboratory that serves the cardiac emergency room of a university hospital in Pernambuco. This text fits the importance of the subject, which is directly related to the good practices of quality, and, principally, with patients' safety ${ }^{(4)}$.

\section{REFERENCES}

1. HOWANITZ P. J. et al. Laboratory critical values, policies and procedures: a College of American Pathologists Q-Probes study in 623 institutions. Arch Pathol Lab Med, v. 126, n. 6, p. 663-9, 2002.

2. KOST, G. J. Critical limits for urgent clinician notification at US medical centers.JAMA, v. 263, n. 5, p. 704-7, 1990.

3. SBPC/ML. Comissão de Acreditação de Laboratórios Clínicos (CALC) - Norma do Programa de Acreditação de Laboratórios Clínicos (PALC), versão 2013.

4. TORRES, D. 0. C. et al. Implantação, validação e revisão da lista de valores críticos em um pronto-socorro cardiológico.J Bras Patol Med Lab, v. 50, n. 5 , p. 332-8, 2014.

5. VALENSTEIN, P. N. et al. Notification of critical results: a College of American Pathologists Q-Probes study of 121 institutions. Arch Pathol Lab Med, v. 132, n. 12, p. 1862-7, 2008.

Clinical pathologist; master's degree and doctorate in Medicine from Universidade Federal de Minas Gerais (UFMG); professor of Clinical Pathology at UFMG; coordinator of the Medicine Residency Program in Clinical Pathology at Hospital das Clínicas of UFMG; regional president of Sociedade Brasileira de Patologia Clínica/Medicina Laboratorial (SBPC/ML) in Minas Gerais for 2014/2015. 